\title{
Morphological plasticity of root growth under mild water stress increases water use efficiency without reducing yield in maize
}

\author{
Qian Cai ${ }^{1,2}$, Yulong Zhang ${ }^{1}$, Zhanxiang Sun ${ }^{2}$, Jiaming Zheng ${ }^{2}$, Wei Bai ${ }^{2}$, Yue Zhang ${ }^{3}$, Yang Liu ${ }^{2}$, Liangshan Feng ${ }^{2}$, \\ Chen Feng ${ }^{2}$, Zhe Zhang ${ }^{2}$, Ning Yang ${ }^{2}$, Jochem B. Evers ${ }^{4}$, and Lizhen Zhang ${ }^{3}$ \\ ${ }^{1}$ College of Land and Environment, Shenyang Agricultural University, Shenyang, 110161, Liaoning, China \\ ${ }^{2}$ Tillage and Cultivation Research Institute, Liaoning Academy of Agricultural Sciences, Shenyang, 110161, Liaoning, China \\ ${ }^{3}$ College of Resources and Environmental Sciences, China Agricultural University, Beijing, 100193, China \\ ${ }^{4}$ Wageningen University, Centre for Crop Systems Analysis (CSA), Droevendaalsesteeg 1, 6708 PB Wageningen, \\ the Netherlands
}

Correspondence to: Yulong Zhang (ylzsau@163.com) and Zhanxiang Sun (sunzhanxiang@sohu.com)

Received: 22 March 2017 - Discussion started: 31 March 2017

Revised: 25 June 2017 - Accepted: 22 July 2017 - Published: 29 August 2017

\begin{abstract}
A large yield gap exists in rain-fed maize (Zea mays L.) production in semi-arid regions, mainly caused by frequent droughts halfway through the crop-growing period due to uneven distribution of rainfall. It is questionable whether irrigation systems are economically required in such a region since the total amount of rainfall does generally meet crop requirements. This study aimed to quantitatively determine the effects of water stress from jointing to grain filling on root and shoot growth and the consequences for maize grain yield, above- and below-ground dry matter, water uptake (WU) and water use efficiency (WUE). Pot experiments were conducted in 2014 and 2015 with a mobile rain shelter to achieve conditions of no, mild or severe water stress. Maize yield was not affected by mild water stress over 2 years, while severe stress reduced yield by $56 \%$. Both water stress levels decreased root biomass slightly but shoot biomass substantially. Mild water stress decreased root length but increased root diameter, resulting in no effect on root surface area. Due to the morphological plasticity in root growth and the increase in root / shoot ratio, WU under water stress was decreased, and overall WUE for both above-ground dry matter and grain yield increased. Our results demonstrate that an irrigation system might be not economically and ecologically necessary because the frequently occurring mild water stress did not reduce crop yield much. The study helps us to understand crop responses to water stress during a critical water-sensitive period (middle of the crop-growing season) and to mitigate drought risk in dry-land agriculture.
\end{abstract}

\section{Introduction}

Maize (Zea mays L.) is the most important crop globally, and also a major food crop in north-eastern China with an average yield around 5.3 $\mathrm{tha}^{-1}$ (Dong et al., 2017). However, the yield gap to the potential of $10.9 \mathrm{tha}^{-1}$ is still large (Liu et al., 2012), mainly due to frequent summer droughts. Due to the increasing probability of extreme climate events (IPCC, 2007), water stress for agricultural production is likely to increase in this region (Song et al., 2014; Yu et al., 2014) which is detrimental for crop photosynthesis and yield (Richards, 2000).

Although the averaged total rainfall during the cropgrowing season can meet the requirements of rain-fed maize in the semi-arid north-east of China, the yearly and seasonal variations often cause droughts (mostly mild water stress) during summer, resulting in yield loss. Since quantitative information on the effects of water stress on maize performance is lacking, it can be questioned whether irrigation systems using underground water are economically and ecologically required in this situation.

Yield reduction by water stress has been attributed to decreased crop growth (Payero et al., 2006), canopy height (Traore et al., 2000), leaf area index (NeSmith and Ritchie, 1992) and root growth (Gavloski et al., 1992). Crop shoot development and biomass accumulation are greatly reduced by soil water deficit at seeding stage (Kang et al., 2000). Shortduration water deficit during the rapid vegetative growth period causes around $30 \%$ loss in final dry matter (Cakir, 
2004). The reduction in maize yield by water stress can be observed in all yield components such as ear density, number of kernels per ear and kernel weight (Ge et al., 2012), especially for stress during or before the maize silk and pollination period (Claassen and Shaw, 1970). Biomass and harvest index (the ratio of grain yield over total above-ground dry matter) are decreased under water stress during anthesis (Traore et al., 2000).

Water use efficiency (WUE, expressed in kg yield obtained per $\mathrm{m}^{3}$ of water) is notably reduced by severe water stress. However, a moderate water stress at V16 (with 16 fully expanded leaves) and R1 (silking) stages in maize increased WUE (Ge et al., 2012). Intentional irrigation deficits before the maize tasselling stage are often used for improving WUE in regions with serious water scarcity, e.g. the North China Plain (Qiu et al., 2008; Zhang et al., 2017). Under water stress, plant photosynthesis and transpiration decrease due to a decrease in stomatal conductance (Killi et al., 2017) induced by increasing concentration of abscisic acid (ABA) (Beis and Patakas, 2015). However, limited knowledge exists on how much the growth and biomass partitioning between shoot and root in maize is affected by water stress during the middle and late growing stages, and whether changes in root growth and morphology caused by water stress could affect maize yielding and water use efficiency.

Since field experiments that aim to quantify the effects of water stress are difficult to carry out in rain-fed agriculture, a mobile rain shelter is often used in studies to control water stress in the field (NeSmith and Ritchie, 1992). The objective of this study was to quantify maize shoot and root growth, grain yield and WUE under different water stress levels during the middle of the crop-growing season with a well-controlled mobile rain shelter to understand the crop response to water stress.

\section{Materials and methods}

\subsection{Experimental design}

The experiments were conducted at Shenyang $\left(41^{\circ} 48^{\prime} \mathrm{N}\right.$, $123^{\circ} 23^{\prime} \mathrm{E}$ ), Liaoning province, north-eastern China in 2014 and 2015. The experimental site is $45 \mathrm{~m}$ above sea level. On average from 1965 to 2015, annual potential evaporation is $1445 \mathrm{~mm}$, with a total precipitation $720 \mathrm{~mm}$, and mean air temperature $8{ }^{\circ} \mathrm{C}$. The frost-free period is $150-170$ days. Average relative humidity is $63 \%$. Annual mean wind speed is $3.1 \mathrm{~m} \mathrm{~s}^{-1}$. The climate is a typical continental monsoon climate with four distinct seasons, characterized by a hot summer and cold winter. The annual mean air temperature was $9.5^{\circ} \mathrm{C}$ in 2014 and $9.1{ }^{\circ} \mathrm{C}$ in 2015 . The mean air temperature during the crop-growing season (May to September) was $20.2^{\circ} \mathrm{C}$ in 2014 and $19.4^{\circ} \mathrm{C}$ in 2015 (Fig. 1).

Maize plants were grown in pots in three treatments: (1) no water stress, (2) mild water stress and (3) severe water stress

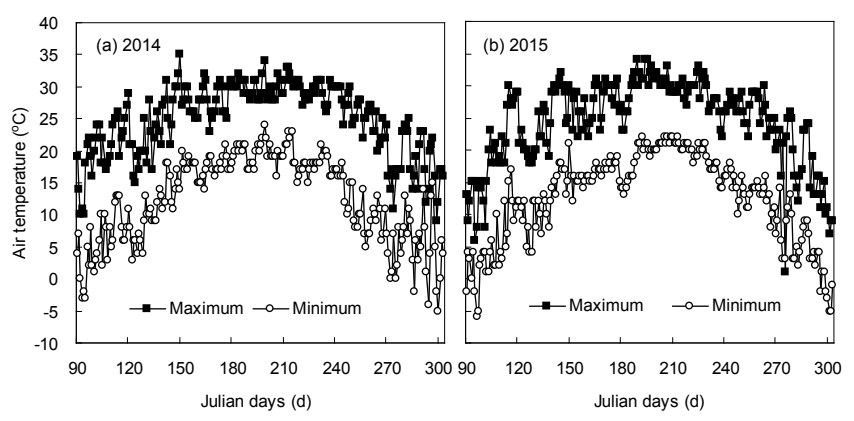

Figure 1. Daily maximum and minimum air temperatures in 2014 and 2015 in Shengyang, Liaoning, China.

(Table 1). The levels of water stress were based on historical rainfall frequency analysis. The water supply was controlled by a mobile rain shelter with a steel frame and transparent PVC cover. The mobile rain shelter is built on a mechanical movement track equipped with an electricity motor to move the shelter with a remote control. The shelter was moved away from the experimental plots on no rain days and covered before the rain came; therefore the effect of shelter on incoming radiation could be ignored. The mobile rain shelter is $9 \mathrm{~m}$ in width, $30 \mathrm{~m}$ in length and $4.5 \mathrm{~m}$ in height. The top and both sides of the shelter have transparent PVC boards to prevent outside rainfall from entering. There is a water gutter outside the movement track to drain the rainwater. Therefore the rainwater intrusion can be avoided. Water treatments began from maize jointing (V6, with 6 fully expended leaves) to filling stages (R3, milk) (Abendroth et al., 2011). Water treatments were conducted by supplying irrigation once every 5 days before starting water treatments with the same amount for all pots, and once every 3 days during the period of water treatment. The amount of water supplied to each treatment is listed in Table 1. The experiments entailed a completely randomized block design with three replicates. Each treatment consisted of 12 pots (one plant per pot) and was divided into 3 replicates (4 pots each). At each sampling (4 samplings in total at an interval of approximately 30 days), one pot was used.

Each pot was $40 \mathrm{~cm}$ in diameter and $50 \mathrm{~cm}$ in height, filled with $40 \mathrm{~kg}$ naturally dried soil with a bulk density of $1.31 \mathrm{~g} \mathrm{~cm}^{-3}$. The large size of pots in the experiments effectively avoided the space effect for growing good maize. The soil was sandy loam with a $\mathrm{pH}$ of 6.15 , total $\mathrm{N}$ of $1.46 \mathrm{~g} \mathrm{~kg}^{-1}$, total of P $0.46 \mathrm{~g} \mathrm{~kg}^{-1}$ and total $\mathrm{K}$ of $12.96 \mathrm{~g} \mathrm{~kg}^{-1}$. $46.5 \mathrm{~g}$ compound fertilizer ( $\mathrm{N} 15 \%, \mathrm{P}_{2} \mathrm{O}_{5} 15 \%$ and $\left.\mathrm{K}_{2} \mathrm{O} 15 \%\right)$ and $15.5 \mathrm{~g}$ diammonium phosphate $\left(\mathrm{N} 18 \%^{2}\right.$ and $\left.\mathrm{P}_{2} \mathrm{O}_{5} 46 \%\right)$ were applied to each pot before sowing. No other fertilizer was applied during the maize-growing season. Maize cultivar used in both years was Liaodan 565, a local commonly used drought-resistant cultivar. One plant was grown in each pot. Maize was sown on 13 May and harvested on 30 September in both 2014 and 2015. 
Table 1. Water treatments during crop-growing seasons from 2014 to 2015.

\begin{tabular}{llrrrrr}
\hline \multirow{2}{*}{ Year } & & \multicolumn{3}{c}{ Actual water supply at three growing periods (mm) } \\
\cline { 3 - 7 } & Water & $\begin{array}{r}\text { Initial volumetric } \\
\text { soil moisture } \\
\text { treatment }\end{array}$ & $\begin{array}{r}\text { Early } \\
\left(16-29 \text { DAS }^{*}\right)\end{array}$ & $\begin{array}{r}\text { Middle } \\
(30-102 \text { DAS) }\end{array}$ & $\begin{array}{r}\text { Late } \\
\text { (103-121 DAS) }\end{array}$ \\
& & & & & & \\
\hline 2014 & No stress & 24.4 & 11.9 & 478 & 56 & 545 \\
& Mild stress & 24.8 & 11.9 & 299 & 56 & 366 \\
& Severe stress & 24.9 & 11.9 & 122 & 56 & 190 \\
\hline 2015 & No stress & 25.3 & 11.9 & 510 & 32 & 553 \\
& Mild stress & 25.3 & 11.9 & 334 & 32 & 378 \\
& Severe stress & 24.4 & 11.9 & 159 & 32 & 203 \\
\hline
\end{tabular}

* DAS refers to days after maize sowing.

\subsection{Dry matter and grain yield measurements}

To determine maize dry matter, four plants were harvested on 49 (V6, jointing), 77 (VT, tasselling), 113 (R3, milk) and 141 (R5, dent) days after sowing (DAS) in 2014, and one sampling was done on 132 DAS in 2015. The samples were separated into roots and shoots and oven-dried at $80^{\circ} \mathrm{C}$ for $48 \mathrm{~h}$ until they reached a constant weight. The shoot/root ratio was calculated using measured organ-specific dry matter.

Grain yield was measured by harvesting all cobs in a pot at maize-harvesting time. The grain was sun-dried to a water content of $15 \%$. Yield components, i.e. ear (cob) numbers per plant, kernel numbers per ear and thousand kernel weight were measured for each plot.

\subsection{Root measurements}

Root growth and morphological traits (root length, diameter and surface area) were measured four times during the cropgrowing season on 49, 77, 113, 141 DAS in 2014. All of the roots were collected for each pot at the time of dry matter measurements. Root samples were carefully washed with tap water to remove soil. The cleaned roots were placed on the glass plate of a root system scanner. Scanned root images were analysed by a plant root image analyser WinRHIZO PRO 2009 (Regent Instruments Inc., Canada) to quantify total root length $(\mathrm{m})$, diameter $(\mathrm{mm})$ and surface area $\left(\mathrm{m}^{2}\right)$ per plant (pot).

\subsection{Measuring soil moisture content, water uptake and water use efficiency}

Soil moisture contents were measured by a soil auger at sowing and harvesting times for each plot (three replicates per treatment). Soil cores were taken from the middle pot for each $10 \mathrm{~cm}$ soil layer. After measuring fresh soil weight, soil samples were oven-dried at $105^{\circ} \mathrm{C}$ for approximately $48 \mathrm{~h}$ until a constant weight was reached. The gravimetric soil moisture contents $\left(\%, \mathrm{~g} \mathrm{~g}^{-1}\right)$ measured by soil auger were calculated into volumetric soil moisture content $\left(\%, \mathrm{~m}^{3} \mathrm{~m}^{-3}\right)$ by multiplying them with soil bulk density.

Water uptake (WU) of maize was calculated using a simplified soil water balance equation (Kang et al., 2002). Because the experiments were sheltered, rainfall, drainage and capillary rise of water did not occur in this situation and therefore were not taken into account in the calculation:

$\mathrm{WU}=I+\Delta S$,

where WU $(\mathrm{mm})$ is crop water uptake $(\mathrm{mm})$ during the whole of the crop-growing season, $I$ is the amount of water supplied to each pot $(\mathrm{mm}) . \Delta S$ is the change of total soil water between sowing and harvesting dates.

Water use efficiency (WUE) was calculated by measuring final yield or above-ground dry matter and total WU during the crop-growing season (Zhang et al., 2007).

$\mathrm{WUE}=Y / \mathrm{WU}$,

where WUE $\left(\mathrm{g} \mathrm{m}^{-2} \mathrm{~mm}^{-1}\right.$ or $\left.\mathrm{kg} \mathrm{m}^{-3}\right)$ is water use efficiency expressed in gain yield $\mathrm{WUE}_{Y}$ or dry matter $\mathrm{WUE}_{\mathrm{DM}} . Y$ $\left(\mathrm{g} \mathrm{m}^{-2}\right)$ is grain yield or dry matter.

\subsection{Statistical analysis}

Analysis of variance on yield, WU, WUE and dry matter for shoot and root were performed using a general linear model of SPSS 20 (SPSS Inc., Chicago, USA). The differences between means were evaluated through least significant difference multiple comparison tests at a significant level of 0.05 .

\section{Results}

\subsection{Variation and frequency distribution of rainfall}

The average rainfall during the maize-growing season (May to September) at an experimental site from 1965 to 2015 was $531 \mathrm{~mm}$ with a standard deviation of $134 \mathrm{~mm}$ (Fig. 2a). 
Table 2. Yield and yield components affected by different water stress from 2014 to 2015.

\begin{tabular}{|c|c|c|c|c|c|c|}
\hline \multirow[b]{2}{*}{ Year } & \multirow[b]{2}{*}{$\begin{array}{l}\text { Water } \\
\text { treatment }\end{array}$} & \multirow{2}{*}{$\begin{array}{l}\text { Ear number } \\
\text { ears plant }^{-1}\end{array}$} & \multirow{2}{*}{$\begin{array}{r}\begin{array}{r}\text { Kernel } \\
\text { number }\end{array} \\
\text { kernels ear }^{-1}\end{array}$} & \multirow{2}{*}{$\begin{array}{r}\text { Thousand } \\
\text { kernel weight } \\
\mathrm{g}\end{array}$} & \multirow{2}{*}{$\begin{array}{r}\begin{array}{r}\text { Yield } \\
\text { plant }\end{array} \\
\text { g plant }^{-1}\end{array}$} & \multirow{2}{*}{$\begin{array}{r}\begin{array}{r}\text { Harvest } \\
\text { index }\end{array} \\
\mathrm{g} \mathrm{g}^{-1}\end{array}$} \\
\hline & & & & & & \\
\hline \multirow[t]{3}{*}{2014} & No stress & $2.0 \pm 0.0 \mathrm{a}$ & $354 \pm 32 \mathrm{a}$ & $440 \pm 6.8 \mathrm{a}$ & $301 \pm 33 a$ & $0.36 \pm 0.01 \mathrm{a}$ \\
\hline & Mild stress & $2.0 \pm 0.0 \mathrm{a}$ & $350 \pm 16 a$ & $416 \pm 1.2 b$ & $276 \pm 14 \mathrm{a}$ & $0.37 \pm 0.01 \mathrm{a}$ \\
\hline & Severe stress & $2.0 \pm 0.0 \mathrm{a}$ & $245 \pm 35 b$ & $412 \pm 3.7 b$ & $166 \pm 25 b$ & $0.27 \pm 0.02 b$ \\
\hline \multirow[t]{3}{*}{2015} & No stress & $2.0 \pm 0.0 \mathrm{a}$ & $341 \pm 67 a$ & $426 \pm 12 \mathrm{a}$ & $240 \pm 60 \mathrm{a}$ & $0.29 \pm 0.04 \mathrm{a}$ \\
\hline & Mild stress & $2.0 \pm 0.0 \mathrm{a}$ & $244 \pm 53 a$ & $427 \pm 22 \mathrm{a}$ & $168 \pm 42 \mathrm{ab}$ & $0.25 \pm 0.03 \mathrm{a}$ \\
\hline & Severe stress & $1.3 \pm 0.3 b$ & $172 \pm 46 a$ & $412 \pm 16 \mathrm{a}$ & $81 \pm 22 b$ & $0.17 \pm 0.04 \mathrm{a}$ \\
\hline \multirow[t]{3}{*}{ mean } & No stress & $2.0 \pm 0.2 \mathrm{a}$ & $347 \pm 38 \mathrm{a}$ & $432 \pm 7.5 \mathrm{a}$ & $266 \pm 36 a$ & $0.32 \pm 0.03 a$ \\
\hline & Mild stress & $2.0 \pm 0.0 \mathrm{a}$ & $289 \pm 36 a b$ & $422 \pm 12 \mathrm{a}$ & $214 \pm 32 \mathrm{a}$ & $0.30 \pm 0.03 \mathrm{ab}$ \\
\hline & Severe stress & $1.6 \pm 0.0 \mathrm{~b}$ & $203 \pm 31 b$ & $412 \pm 8.5 \mathrm{a}$ & $118 \pm 23 b$ & $0.21 \pm 0.03 b$ \\
\hline \multirow[t]{3}{*}{$P$} & Treatment & 0.021 & 0.003 & 0.556 & 0.005 & 0.013 \\
\hline & Year & 0.184 & 0.514 & 0.889 & 0.237 & 0.039 \\
\hline & Treatment $\times$ year & 0.111 & 0.664 & 0.555 & 0.835 & 0.758 \\
\hline
\end{tabular}

The same lower-case letters indicate no significant difference between water treatments within the same year at $a=0.05$.
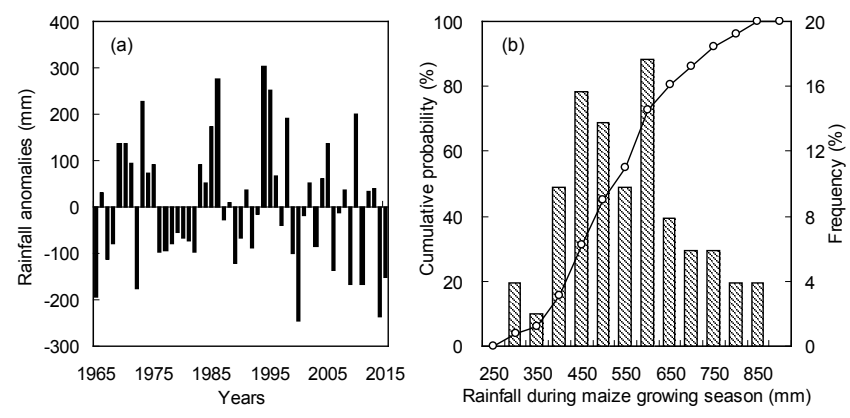

Figure 2. Anomalies and cumulative frequency of rainfall during the maize-growing season (May to September) from 1965 to 2015 at Shengyang, Liaoning.

Rainfall in the experimental years was much less than in a normal year, $296 \mathrm{~mm}$ in 2014 and $379 \mathrm{~mm}$ in 2015 . The frequency of years with rainfall above $500 \mathrm{~mm}$ was $68.6 \%$ over the past 51 years. For years with mild drought stress (350-450 mm), this was $27.5 \%$ and with severe drought stress $(200-300 \mathrm{~mm}$ ) it was $3.9 \%$ (Fig. 2b), indicating that maize growing in this region mainly suffered from mild water stress.

\subsection{Yield and yield components}

The maize yield under mild water stress over 2 years was not significantly different, while in severe stress the yield was $55.6 \%$ lower than in the no water stress control (Table 2). The decrease of maize yield in severe water treatment was due to the decreases in ear and kernel numbers as well as the harvest index (HI). However, water stress did not affect ker- nel weight, while other yield components were decreased. The yearly effect was only significant for HI, which was likely caused by the variation in air temperature: the cooler weather in 2015 during the maize-growing season decreased the HI compared with a warmer year in 2014. There were no interactions between year and treatment.

\subsection{Above- and below-ground dry matter}

Mild water stress did not reduce root dry matter (Fig. 3a, b), but greatly reduced shoot dry matter, especially at grainfilling stage (113 DAS) (Fig. 3c, d). The severe water stress decreased both root and shoot dry matter compared with no stress control, but the magnitude of the decrease in shoot was much larger than in root. At maize tasselling stage (77 DAS), as taproots reached their maximum size, root dry matter under severe water stress was much lower than mild and no water stress treatments. However, it was less different later in the season, which indicated a strong complementarily growth of root system under water stress. Due to the different responses of shoot and root to water stress, the root/shoot ratios under water stress increased (Fig. 3e, f), especially during crop rapid growing period (77 to $113 \mathrm{DAS}$ ).

\subsection{Root length, diameter and total surface area affected by water stress}

Root length per plant was much lower under severe water stress than in the control, especially at the tasselling stage (77 DAS). The decrease of root length under mild water stress during the middle of the maize-growing season was much smaller than under severe stress (Fig. 4a). Root diameters under both mild and severe water stress treatments were 


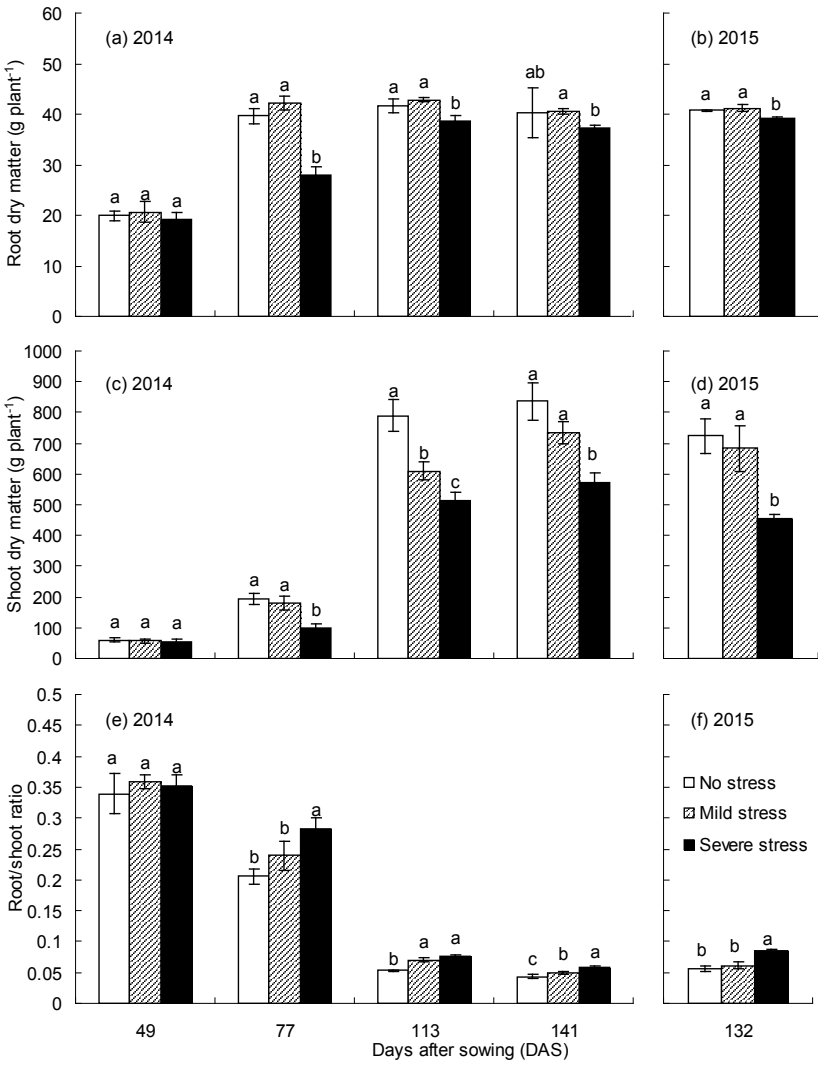

Figure 3. Root and shoot dry matter of maize under water stress at different growing stages in 2014-2015.

much higher than under the no water stress control (Fig. 4b), especially during the late growing season. The total root surface area was less changed (Fig. 4c), especially during the reproductive growth period (113 DAS).

\subsection{Water uptake and use efficiency}

Total water uptake (WU) reduced by $28.9 \%$ under mild water stress and by $54.6 \%$ under severe stress compared with no stress control (588 mm) (Fig. 5). Water use efficiency for maize above-ground dry matter (WUE $\mathrm{DM}_{\mathrm{DM}}$ ) under both water stress treatments across all years increased by $31.2 \%$ compared with no stress control (Fig. 5b). The WUE $\mathrm{DM}_{\mathrm{DM}}$ in severe water stress was the highest $\left(14.4 \mathrm{~kg} \mathrm{~m}^{-3}\right)$, which was $42.2 \%$ higher than the control, while that in mild stress increased by $20.2 \%$. However, WUE for grain yield under severe water stress $\left(3.51 \mathrm{~kg} \mathrm{~m}^{-3}\right)$ was not significantly different from that in the control $\left(3.38 \mathrm{~kg} \mathrm{~m}^{-3}\right)$, while $\mathrm{WUE}_{Y}$ in mild water stress over 2 years increased by $17.3 \%$ (Fig. 5c). The difference between WUEs in dry matter and grain yield was due to the extent of decreasing HI under the levels of water stress (Table 2).
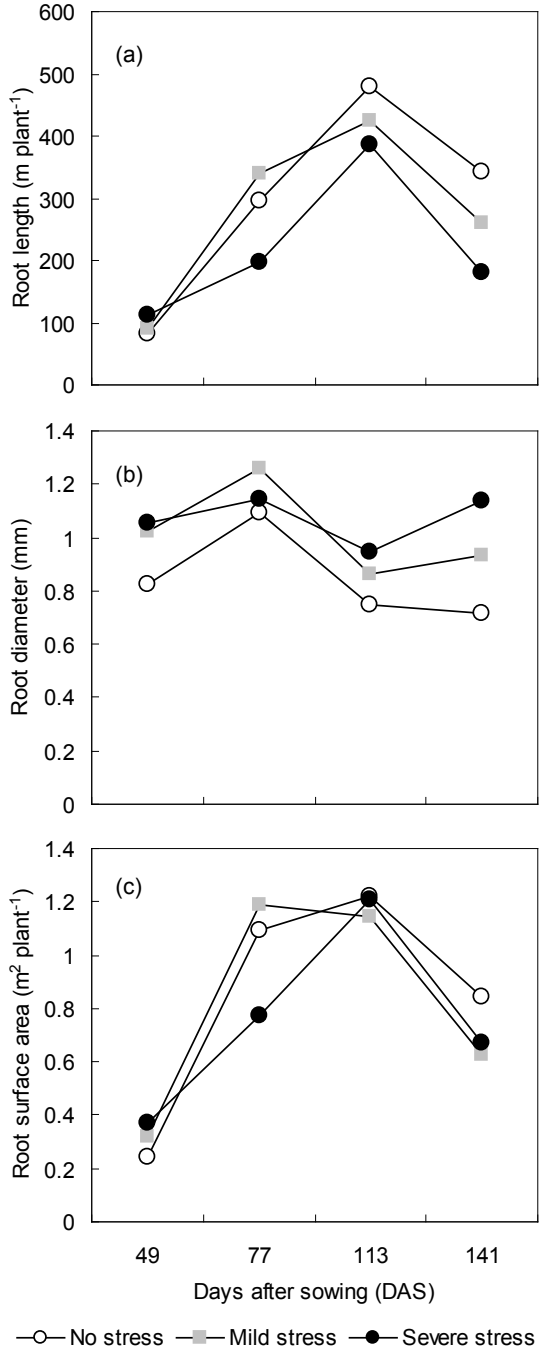

Figure 4. Total root length, average diameter and total surface area per plant affected by water stress in 2014 .

\section{Discussion}

Mild water stress from maize jointing (V6) to filling stages (R3) did not significantly reduce maize grain yield. This is different from a previous report which claimed that maize yield is much more affected by water stress during the flowering stage than at other stages (Doorenbos et al., 1979). Our result differed from a previous study, which showed that mild water stress seriously reduced crop production (Kang et al., 2000). This is likely due to our choice of a drought-resistant variety (Zhengdan 565) and the difference in ecological zones. Genotype-dependent relationships between yield and crop growth rate would be stronger under water stress than under the no stress condition (Lake and Sadras, 2016).

Mild water stress during the middle of the crop-growing period can maintain maize yield but substantially reduces the water consumption at the same time in our study. Thus, the 

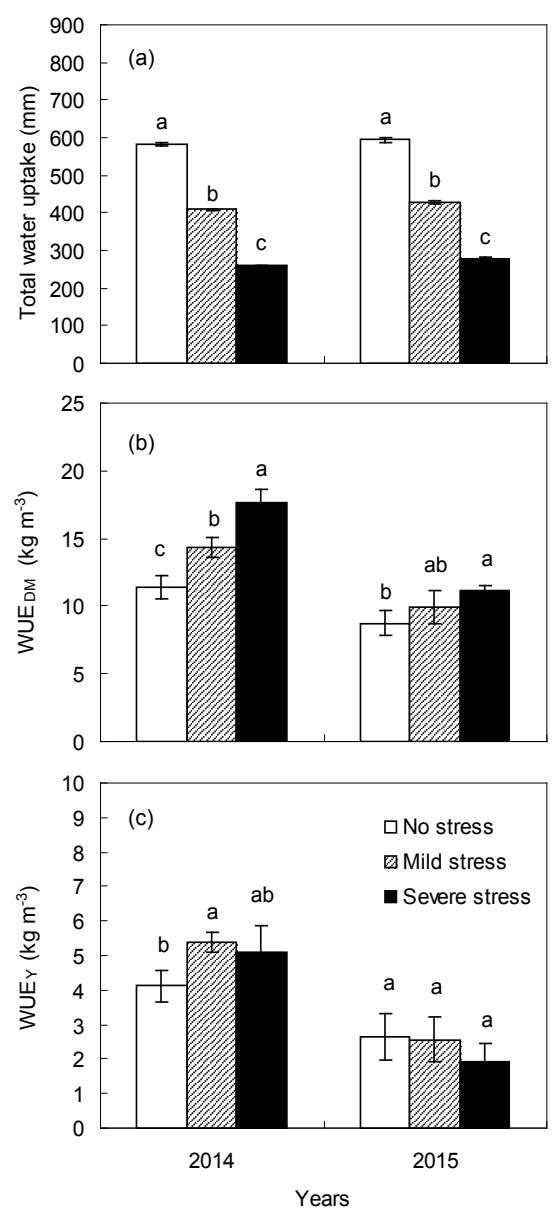

Figure 5. Total water uptake (WU) during the crop-growing season and water use efficiency for above-ground dry matter (WUE ${ }_{D M}$ ) and grain yield $\left(\mathrm{WUE}_{Y}\right)$ under water stress in 2014-2015.

water use efficiency was increased (Liu et al., 2016). Mild water stress reduced total water uptake, resulting in a $20.2 \%$ higher WUE in dry matter and $17.3 \%$ in yield. The increase in WUE under mild water stress benefitted from the morphological responses of shoot and root growth to water stress with an increase in root / shoot ratio. The water stress reduced root length; however, this reduction was compensated by an increase in root diameter. The maintenance of crop growth under water deficit was limited by the severity of the stress. Under severe water stress, maize growth fails to be compensated by plant plasticity.

Severe water stress greatly reduced both shoot and root biomass. A large decrease in shoot growth, i.e. less biomass and leaf area, reduces the light interception and transpiration (Monteith, 1981). Under mild water stress during vegetative and tasselling stages, the shoot growth was not significantly reduced in this study but was in a previous report, e.g. in plant height and leaf area (Cakir, 2004). Mild soil water deficit may also reduce water loss of plants through physiological regulation (Davies and Zhang, 1991). Moderate soil drying at the vegetative stage encourages root growth and distribution in deep soil (Jupp and Newman, 1987; Zhang and Davies, 1989), which is consistent with our findings. A large root system with deep distribution is beneficial for water-limited agriculture (McIntyre et al., 1995). These mechanisms explained why maize yield under mild water stress did not decrease in our study.

We found an increase in root diameter under water stress. This result indicated that there were fewer lateral roots under water stress than under no water stress. This may limit water absorption since the lateral roots is younger and more active in uptake function (Lynch, 1995). Average root diameters in all treatments decreased from 77 to 113 DAS, which was caused by highly emerged lateral roots after the taproot reached its maximum (VT stage). The higher root diameter under water stress than in the no water stress control at 141 DAS was probably due to a fast senescence of latedeveloped lateral roots.

Our results on root morphological plasticity under mild water deficit provided more evidence for the explanation of enhancing WUE and maintaining yielding in relation to the crop-water response. However, the mechanism that determines the crop response to water stress may also involve other processes, e.g. intercellular $\mathrm{CO}_{2}$, stomatal conductance, photosynthetic rate, oxidative stress, sugar signaling, membrane stability and root chemical signals (Xue et al., 2006; Dodd, 2009). The relationship between carbon assimilation and water stress has been widely explored to understand the physiological mechanism for improving WUE (Ennahli and Earl, 2005; Xue et al., 2006; Zhang et al., 2013). The abscisic acid (ABA)-based drought stress chemical signals regulate crop vegetative and reproductive development and contribute to crop drought adaptation (Killi et al., 2017). Increased concentration of ABA in the root induced by soil drying may maintain root growth and increase root hydraulic conductivity, thus alleviating the water deficit in the shoot (Liu et al., 2005). The increase of ABA can also induce stomatal closure and reduce crop transpiration (Haworth et al., 2016), net photosynthesis and crop growth (Killi et al., 2017).

The maize yield in 2015 was much lower than in 2014 independent of water stress. That might be caused by a higher maximum air temperature in $2015\left(32.0^{\circ} \mathrm{C}\right)$ than in 2014 $\left(29.1^{\circ} \mathrm{C}\right)$ during the flowering period. High air temperature reduces maize pollination (Muller and Rieu, 2016) and directly affects yield formation and $\mathrm{HI}$.

\section{Conclusions}

This study clearly demonstrates that the maize yield under mild water stress during summer does not decrease but the water use efficiency increases due to changes in root and shoot growth. A higher root / shoot ratio under mild water stress allows plants to efficiently use limited soil water. In the studied region (Liaoning province), maize mainly grows 
in rain-fed conditions (2.4 million ha), covering $73 \%$ of the total area for grain crops. To reduce the possible effect of drought on maize production, a well system that pipes ground-water to irrigate crops has recently been planned. The wells need to be 60 to $70 \mathrm{~m}$ deep and have an average cost of 12000 Yuan each. Each well can only irrigate 9 to 10 ha of maize. According to our results, only severe water stress significantly reduces maize yield by $55.6 \%$ across two experimental years (Table 2), which occurs only $3.9 \%$ during 1965 to 2015 . Mild water stress occurs much frequently (27.5\% of years); however, it does not significantly affect maize yield. Our study suggested that the well system in this region might not be economically and ecologically necessary. Other agronomy practices such as intercropping maize with crops requiring less water (e.g. peanut), cultivar selection, adjusting sowing windows (Liu et al., 2013; Lu et al., 2017) and ridge-furrow with covering plastic film (Dong et al., 2017) are likely more applicable in optimizing crop yield and regional sustainability. Our study provides more evidence to understand crop responses to water stress, especially in relation to root morphological plasticity in a drought environment. The results can be further applied by combining them with a crop model (Mao et al., 2015) to mitigate climate risk in dry-land agriculture.

Data availability. The data are available at http://pan.baidu.com/s/ 1skGRASd and in the Supplement.

\section{The Supplement related to this article is available online at https://doi.org/10.5194/bg-14-3851-2017-supplement.}

Author contributions. ZS, YZ, JZ and QC conceived and designed the experiments. QC, WB, YZ, YL, LF, CF, ZZ and NY performed the experiments. LZ, QC and JBE analysed the data and wrote the paper.

Competing interests. The authors declare that they have no conflict of interest.

Special issue statement. This article is part of the special issue "Ecosystem processes and functioning across current and future dryness gradients in arid and semi-arid lands". It is not associated with a conference.

Acknowledgements. This research was supported by the National key research and development programme of China (2016YFD0300204), the International Cooperation and Exchange (31461143025) and the Youth Fund (31501269) of the National Science Foundation of China, Liaoning BaiQianWan Talent
Program (201746), Outstanding Young Scholars of National High-level Talent Special Support Program of China.

Edited by: Zisheng Xing

Reviewed by: two anonymous referees

\section{References}

Abendroth, L. J., Elmore, R. W., Boyer, M. J., and Marlay, S. K.: Corn Growth and Development. PMR 1009. Iowa State University Extension, Ames, Iowa, USA, available at: https://store. extension.iastate.edu/Product/Corn-Growth-and-Development (last access: 8 June 2017), 2011.

Beis, A. and Patakas, A.: Differential physiological and biochemical responses to drought in grapevines subjected to partial root drying and deficit irrigation, Eur. J. Agron., 62, 90-97, 2015.

Cakir, R.: Effect of water stress at different development stages on vegetative and reproductive growth of corn, Field Crop Res., 89, 1-16, 2004.

Claassen, M. M. and Shaw, R. H.: Water deficit effects on corn. II. Grain components, Agron. J., 62, 652-655, 1970.

Davies, W. J. and Zhang, J.: Root signals and the regulation of growth and development of plants in drying soil, Ann. Rev. Plant Phys., 42, 55-76, 1991.

Dodd, I. C.: Rhizosphere manipulations to maximize "crop per drop" during deficit irrigation, J. Exp. Bot., 60, 2454-2459, 2009.

Dong, W., Zhang, L., Duan, Y., Sun, L., Zhao, P., van der Werf, W., Evers, J. B., Wang, Q., Wang, R., and Sun, Z.: Ridge and furrow systems with film cover increase maize yields and mitigate climate risks of cold and drought stress in continental climates, Field Crops Res., 207, 71-78, 2017.

Doorenbos, J., Kassam, A. H., Bentvelsen, C., and Uittenbogaard, G.: Yield response to water, FAO Irrigation and Drainage Paper No. 33, FAO, Rome, Italy, 193 pp., 1979.

Ennahli, S. and Earl, H. J.: Physiological limitations to photosynthetic carbon assimilation in cotton under water stress, Crop Sci., 45, 2374-2382, 2005.

Gavloski, J. E., Whitfield, G. H., and Ellis, C. R.: Effect of restricted watering on sap flow and growth in corn (Zea mays L.), Can. J. Plant Sci., 72, 361-368, 1992.

Ge, T., Sui, F., Bai, L., Tong, C., and Sun, N.: Effects of water stress on growth, biomass partitioning, and water-use efficiency in summer maize (Zea mays L.) throughout the growth cycle, Acta Physiol. Plant., 34, 1043-1053, 2012.

Haworth, M., Cosentino, S.L., Marino, G., Brunetti, C., Scordia, D., Testa, G., Riggi, E., Avola, G., Loreto, F., and Centritto, M.: Physiological responses of Arundo donax ecotypes to drought: a common garden study, Glob. Change Biol. Bioenergy, 9, 132 143, https://doi.org/10.1111/gcbb.12348, 2016.

IPCC: Climate change, 2007, The physical science basis, in: Contribution of working group I to the fourth assessment report of the intergovernmental panel on climate change, edited by: Solomon, S., Qin, D., Manning, M., Chen, Z., Marquis, M., Averyt, K. B., Tignor, M., Miller, H. L., Cambridge University Press, Cambridge, 996 pp., 2007.

Jupp, A. P. and Newman, E. I.: Morphological and anatomical effects of severe drought on the roots of Lolium perenne L., New Phytol., 105, 393-402, 1987. 
Kang, S. Z., Shi, W. J., and Zhang, J. H.: An improved water-use efficiency for maize grown under regulated deficit irrigation, Field Crops Res., 67, 207-214, 2000.

Kang, S. Z., Zhang, L., Liang, Y. L., Hu, X. T., Cai, H. J., and Gu, B. J.: Effects of limited irrigation on yield and water use efficiency of winter wheat in the Loess Plateau of China, Agr. Water Manage., 55, 203-216, 2002.

Killi, D., Bussotti, F., Raschi A., and Haworth, M.: Adaptation to high temperature mitigates the impact of water deficit during combined heat and drought stress in $\mathrm{C} 3$ sunflower and $\mathrm{C} 4$ maize varieties with contrasting drought tolerance, Physiol. Plant., 159, 130-147, 2017.

Lake, L. and Sadras, V. O.: Screening chickpea for adaptation to water stress: Associations between yield and crop growth rate, Eur. J. Agron., 81, 86-91, 2016.

Liu, E. K., Mei, X. R., Yan, C. R., Gong, D. Z., and Zhang, Y. Q.: Effects of water stress on photosynthetic characteristics, dry matter translocation and WUE in two winter wheat genotypes, Agr. Water Manage., 167, 75-85, 2016.

Liu, F., Jensen, C. R., and Andersen, M. N.: A review of drought adaptation in crop plants: changes in vegetative and reproductive physiology induced by ABA-based chemical signals, Australian J. Agr. Resour., 56, 1245-1252, 2005.

Liu, Z. J., Yang, X. G., Hubbard, K. G., and Lin, X. M.: Maize potential yields and yield gaps in the changing climate of northeast China, Glob. Change Biol., 18, 3441-3454, 2012.

Liu, Z. J., Hubbard, K. G., Lin, X. M., and Yang, X. G.: Negative effects of climate warming on maize yield are reversed by the changing of sowing date and cultivar selection in Northeast China, Glob. Change Biol., 19, 3481-3492, 2013.

Lu, H., Xue, J., and Guo, D.: Efficacy of planting date adjustment as a cultivation strategy to cope with drought stress and increase rainfed maize yield and water-use efficiency, Agr. Water Manage., 179, 227-235, 2017.

Lynch, J. P.: Root architecture and plant productivity, Plant Physiol., 109, 7-13, 1995.

Mao, L., Zhang, L., Evers, J. B., van der Werf, W., Wang, J., Sun, H., Su, Z., and Spiertz, H.: Resource use, sustainability and ecological intensification of intercropping systems, J. Integr. Agr., 14, 1442-1550, 2015.

McIntyre, B. D., Riha, S. J., and Flower, D. J.: Water uptake by pearl millet in a semiarid environment, Field Crops Res., 43, 6776, 1995.

Monteith, J. L.: Coupling of plants to the atmosphere, in: Grace, J., Ford, E. D., and Jarvis, P. G., Plants and their Atmospheric Environment, Blackwell, Oxford, 1-29, 1981.
Muller, F. and Rieu, I.: Acclimation to high temperature during pollen development, Plant Reprod., 29, 107-118, 2016.

NeSmith, D. S. and Ritchie, J. T.: Short- and long-term responses of corn to pre-anthesis soil water deficit, Agron. J., 84, 107-113, 1992.

Payero, J. O., Melvin, S. R., Irmak, S., and Tarkalson, D.: Yield response of corn to deficit irrigation in a semiarid climate, Agr. Water Manage., 84, 101-112, 2006.

Qiu, G. Y., Wang, L. M., He, X. H., Zhang, X. Y., Chen, S. Y., Chen, J., and Yang, Y. H.: Water use efficiency and evapotranspiration of winter wheat and its response to irrigation regime in the north China plain, Agr. Forest Meteorol., 148, 1848-1859, 2008.

Richards, A.: Selectable traits to increase crop photosynthesis and yield of grain crops, J. Exp. Bot., 51, 447-458, 2000.

Song, X. Y., Li, L. J., Fu, G. B., Li, J. Y., Zhang, A. J., Liu, W. B., and Zhang, K.: Spatial-temporal variations of spring drought based on spring-composite index values for the Songnen Plain, Northeast China, Theor. Appl. Climatol., 116, 371-384, 2014.

Traore, S. B., Carlson, R. E., Pilcher, C. D., and Rice, M. E.: Bt and Non-Bt maize growth and development as affected by temperature and drought stress, Agron. J., 92, 1027-1035, 2000.

Xue, Q. W., Zhu, Z. X., Musick, J. T., Stewart, B. A., and Dusek, D. A.: Physiological mechanisms contributing to the increased water-use efficiency in winter wheat under deficit irrigation, J. Plant Physiol., 163, 154-164, 2006.

Yu, X. Y., He, X. Y., Zheng, H. F., Guo, R. C., Ren, Z. B., Zhang, D., and Lin, J. X.: Spatial and temporal analysis of drought risk during the crop-growing season over northeast China, Nat. Hazards, 71, 275-289, 2014.

Zhang, J. and Davies, W. J.: Abscisic acid produced in dehydrating roots may enable the plant to measure the water status of the soil, Plant Cell Environ., 12, 73-81, 1989.

Zhang, J., Sun, J. S., Duan, A., Wang, J. L., Shen, X. J., and Liu, X. F.: Effects of different planting patterns on water use and yield performance of winter wheat in the Huang-Huai-Hai plain of China, Agr. Water Manage., 92, 41-47, 2007.

Zhang, X., Qin, W., Chen, S., Shao, L., and Sun, H.: Responses of yield and WUE of winter wheat to water stress during the past three decades - A case study in the North China Plain, Agr. Water Mange., 179, 47-54, 2017.

Zhang, X., Wang, Y., Sun, H., Chen, S., and Shao, L.: Optimizing the yield of winter wheat by regulating water consumption during vegetative and reproductive stages under limited water supply, Irrig. Sci., 31, 1103-1112, 2013. 